\title{
Search for a New Editor in Chief
}

I n 1998, Gilbert E. D’Alonzo Jr, DO, became the editor in chief of the American Osteopathic Association (AOA), having served as a contributing editor (the precursor of the associate editor position) of The Journal of the American Osteopathic Association (JAOA) before being named editor in chief. Since that time, Dr D'Alonzo has steered not only the JAOA, the JAOA supplements, and The DO online magazine, but also the AOA's custom publications and Web programs on medical topics relevant to osteopathic physicians. He is now embracing his next step: retirement from the AOA editorship.

During Dr D'Alonzo's tenure as editor in chief, the AOA publications have gained in stature, audience, and recognition, both inside and outside the osteopathic medical community. The JAOA is mailed to more than 39,000 individuals, and its electronic tables of contents reach more than 80,000 individuals. In terms of metrics, from 2011 to 2012 the $J A O A$ saw a $20 \%$ increase in average number of unique visitors per month and a $29 \%$ increase in visits to the site. In addition to popular sections such as medical education and letters to the editor, the "Clinical Images" and "In Your Words" sections were recently added. However, the most frequently read content remains review articles and clinical practice articles, followed by original contributions.

The DO magazine's move to an online-only presence in 2009 has resulted in an even wider readership than when it was published only in print. From 2011 to 2012 , visits to the site increased by $161 \%$, and the number of unique visitors to the site increased by $163 \%$. Articles in the magazine cover myriad topics of interest to the osteopathic medical community. Of note, both The New York Times and Forbes magazine have linked to articles from The DO.
With Dr D'Alonzo's retirement, the AOA begins the search for a new editor in chief to continue the remarkable growth of the AOA's publications. In brief, the AOA editor in chief is responsible for the following: directing the editorial content of publications produced by the AOA Division of Publications, including the $J A O A$, The DO, supplements to the $J A O A$, and custom publications; soliciting highquality manuscripts on topics of relevance; writing editorials on timely and pertinent issues; and engaging with the $J A O A$ Editorial Advisory Board, the $J A O A$ Editorial Board, the osteopathic community, and the medical research community.

The search for the next AOA editor in chief will be led by AOA Board of Trustee members Joseph M. Yasso Jr, DO, chair, and William J. Burke, DO, as well as Dr D'Alonzo. Interested physicians are invited to send their curricula vitae (marked "confidential”) to EICSearch@osteopathic.org. Visit http:// www.osteopathic.org/EICsearch for more information about the position and the responsibilities of the AOA editor in chief. (doi:10.7556/jaoa.2013.016)

๑) 2013 American Osteopathic Association 